\title{
Individual habitat use and behavior of acoustically-tagged juvenile green sturgeon in the Sacramento-San Joaquin Delta
}

\author{
Michael J. Thomas 1 - Matthew L. Peterson • \\ Eric D. Chapman • Nann A. Fangue • A. Peter Klimley
}

Received: 1 June 2017 / Accepted: 9 June 2019 /Published online: 28 June 2019

(C) The Author(s) 2019

\begin{abstract}
Southern distinct population segment (sDPS) juvenile Green Sturgeon are thought to rear in the Sacramento-San Joaquin Delta for two to four years. The southern population segment has been listed as "threatened" under the Endangered Species Act. Habitat loss is cited as a significant driver in declines of the population. Specific to juvenile rearing, much of the historic floodplain habitat has been lost and replaced by leveed channelized waterways. In addition to geomorphic alterations, other direct and indirect activities such as water export, dredging, and the introduction of invasive species may have significant impacts to the viability of the species. The objective of this tracking study was to provide a first of its kind look at the movements and behaviors of wild caught juvenile Green Sturgeon within the putative nursery grounds of the Sacramento-San Joaquin Delta. We acoustically tagged and continuously tracked six yearling juvenile Green Sturgeon with mean total length (TL) of $50.6 \mathrm{~cm}$ $(\mathrm{SD}=5.3)$ and mean mass of $563.3 \mathrm{~g}(\mathrm{SD}=151.7)$. We performed continuous mobile tracking for a period of up to five days per individual while recording GPS
\end{abstract}

M. J. Thomas $(\bowtie) \cdot$ E. D. Chapman · N. A. Fangue

A. P. Klimley

Biotelemetry Laboratory, Department of Wildlife, Fish \&

Conservation Biology, University of California, Davis, One

Shields Avenue, Davis, CA 95616, USA

e-mail: mjthomas@ucdavis.edu

M. L. Peterson

FISHBIO, 180 E. Fourth Street, Suite 160, Chico, CA 95928, USA coordinates, depths, and water temperature at the sturgeon's location. We used first-passage times, defined as the amount of time spent within a given area, for which a radius was determined post hoc. First passage times were used as a metric for parsing bouts of localized movements from directed movements. Our results indicate that juvenile Green Sturgeon largely oriented at or near the bottom. Depths utilized by all sturgeon ranged from $>3 \mathrm{~m}$ to $20 \mathrm{~m}$ across all tracks. Individuals exhibited fidelity to the San Joaquin River Channel with only one individual leaving the main channel. Juvenile green sturgeon were shown to exhibit both positive and negative rheotaxis during sustained directed movements under independent ebb tidal cycles. This study provides the first detailed examination into the early life movements and behaviors of a rare species within their putative nursery grounds.

Keywords Acoustic telemetry - Green sturgeon · Habitat utilization $\cdot$ First-passage time

\section{Introduction}

The juvenile life stage is the least understood within the complex life cycle of the Green Sturgeon (Acipenser medirostris). This is not surprising given the cryptic behavior, small population size, lack of commercial value, and the complexity of habitats in which sturgeon occupy. In April of 2006, Sacramento River Green Sturgeon, classified as the southern distinct population segment (sDPS), were listed as "threatened" under the 
federal Endangered Species Act (National Marine Fisheries Service 2006). The criteria for listing included loss of historical habitat, substantial decline in population numbers, and limited knowledge regarding the basic biology (Adams et al. 2005; National Marine Fisheries Service 2006).

Green Sturgeon are an anadromous fish species that spend the majority of their adult lives in the northeast Pacific Ocean along the western coast of North America (Lindley et al. 2008; Moser et al. 2016). They return to their natal waters approximately every two to four years to spawn (Erickson and Webb 2007). During the spring (April through June) reproductively mature Green Sturgeon arrive at the upper reaches of the Sacramento River to spawn (Heublein et al. 2009). Larval Green Sturgeon begin emerging from the gravel in early April, with peak abundance occurring during May and June (Poytress et al. 2015). There is uncertainty around when young of year (YOY) Green Sturgeon leave the natal spawning ground and begin emigration to the putative rearing grounds of the Sacramento-San Joaquin Delta (SSJ Delta). It is likely that downstream emigration from the spawning grounds begins in early to late fall when water temperatures fall below the optimum necessary to promote grow (Mayfield and Cech 2004). Juveniles may spend the next two to three years rearing in the complex network of waterways known as the SSJ Delta and the San Francisco estuary (Moyle 2002).

To date, telemetry studies of Green Sturgeon have focused on marine migrations of adults (Erickson and Hightower 2007; Lindley et al. 2008), estuarine usage by adults (Kelly et al. 2007; Moser and Lindley 2007), and riverine spawning migrations of adults (Erickson et al. 2002; Erickson and Webb 2007; Thomas et al. 2013; Thomas et al. 2014). In contrast, little attention has been given to the behavior and use of SSJ Delta habitats during juvenile Green Sturgeon life stages. Radtke (1966) captured juvenile Green Sturgeon in gill nets near the Santa Clara shoals within the SSJ Delta. These hostoric captures may provide some qualitative evidence regarding the seasonal presence and spatial distribution of juveniles in the SSJ Delta. While results from this study show numerous sites throughout the SSJ Delta were sampled, most resulted in a zero catch. Several sites resulted in Green Sturgeon captures throughout the seasons; however, catch per unit effort at these locations never exceeded 1. CPUE at Santa Clara Shoals was the exception, yielding the highest $\mathrm{CPUE}=23$, though increased catches were limited to the summer season (June-August). It is important to note that since Radtke (1966) there have been significant changes in water export operations that have affected the hydrodynamics of the delta ecosystem.

The majority of our knowledge about juvenile Green Sturgeon comes from ongoing salmonid and sport fishing monitoring programs. Young of the year (YOY) juvenile Green Sturgeon ranging in size from 26 to $34 \mathrm{~mm}$ are captured in screw traps operated at the Red Bluff Diversion Dam (Brown 2007; Poytress et al. 2015). Juvenile Green Sturgeon are periodically captured at the Glenn-Colusa Irrigation District (GCID) monitoring site, Central Valley Water Project and State Water Project (hereafter south SJJ Delta pumping facilities). Juveniles captured at the south SSJ Delta pumping facilities range in size from 30 to $40 \mathrm{~cm}$ (Adams et al. 2007), and primarily consist of age1 juveniles (Beamesderfer et al. 2007). Green Sturgeon are periodically captured during White Sturgeon monitoring in San Pablo Bay, though often of larger size than individuals in the SSJ Delta (DuBoise et al. 2010). While each of these programs has provided some information about interannual trends of Green Sturgeon abundance, each are site specific, size selective, and have large distances between collection sites. Hence, these data points are not sufficient to describe the movement behaviors or habitat use at any particular geographic scale.

Information from monitoring studies of other species does provide a coarse picture of early life movement patterns of juvenile Green Sturgeon. In the upper river, captures of juvenile Green Sturgeon peak between May and June (Poytress et al. 2015). It is believed that young of the year begin their downriver migration to the SSJ Delta at the onset of winter, as temperatures in the upper watershed drop below the thermal optima $\left(15-19^{\circ} \mathrm{C}\right)$ for growth at this life stage (Mayfield and Cech 2004; Poletto et al. 2018; Hamda et al. 2019). Typically, the lower reaches of the Sacramento River and SSJ Delta are warmer in the winter months compared to upstream habitats and may result in accelerated growth. Juveniles undergo physiological changes similar to salmonids for osmoregulation (pseudo-smoltification) by age-2 (Allen and Cech 2007; Poletto et al. 2013). Once juveniles are capable of osmoregulation, ocean entry becomes a possibility, though there is no study to date that has actually looked at these relationships in timing. The presence of juveniles residing within the SSJ Delta in size ranges greater than those reported for when osmoregulation is possible may suggest residence does occur regardless of timing of pseudo-smoltification. 
This study was initiated to provide a description of the movements and behavior of wild juvenile Green Sturgeon opportunistically capture in two separate years (2008 and 2010). Further, our specific objective was to describe the fine scaled movements of juvenile sDPS Green Sturgeon with the specific objective of describing the fine scale movements at a location within the central SSJ Delta where they have been observed and documented in the past.

\section{Methods}

Study area

The tidally influenced SSJ Delta at the confluence of the Sacramento and San Joaquin Rivers is the largest delta system along the coast of western North America. There are approximately 159,600 ha of open water and wetland, $2600 \mathrm{~km}$ of tidal waterways, and an additional $1600 \mathrm{~km}$ of fluvial channels that are tidally influenced (Whipple et al. 2012). The Sacramento River contributes $73 \%$ of the water from the north, the San Joaquin River supplies $21 \%$ from the south, with the remaining $6 \%$ contributed by smaller rivers to the east (California Department of Water Resources 2013).

This study was conducted in the main-stem San Joaquin River, from the confluence of Potato Slough (B) $\left[38.084236^{\circ},-121.568211^{\circ}\right]$ to the confluence of Three-mile Slough (C) [38.08527 ${ }^{\circ}$, $-121.684818^{\circ}$ ](Fig. 1). This section of the SSJ Delta is characterized by a deep $(10-20 \mathrm{~m})$ channel, leveed banks, and few shoal areas (1-10 $\mathrm{m}$ in depth). The general study location was based on information taken from Radtke (1966), who documented the seasonal presence of juvenile Green Sturgeon at Santa Clara Shoals (Fig. 1).

Fish collecting, rearing, and tagging procedures

Five larval sturgeon, two in 2008 and three in 2010, ranging in size from 24 to $28 \mathrm{~mm}$ were captured using rotary screw traps operated by U.S. Fish and Wildlife Service (USFWS) adjacent to the Red Bluff Diversion Dam (RBDD) [RKM 378, measured from the Golden Gate Bridge] in Red Bluff, California (Poytress et al. 2009; Poytress et al. 2010). One juvenile Green Sturgeon (GS1) was captured at the south SSJ Delta pumping facilities located near Tracy, California in
July, 2008. All individuals originating from USFWS were transferred to the U.S. Bureau of Reclamation wet laboratory adjacent to RBDD. Larval sturgeon were reared in a $1.2 \mathrm{~m}$ circular tank filled to a depth of $0.6 \mathrm{~m}$. Tank water at the RBDD facilities was flow through, coming directly from the Sacramento River. Therefore, all temperatures were equivalent to the source and represented the natural thermal regime. When individuals held at the RBDD site reached a size of approximately $50 \mathrm{~mm}$ they were transported to the Center for Aquatic Biology and Aquaculture (CABA) in Davis, California. While at CABA, water temperatures were kept between 15 and $17{ }^{\circ} \mathrm{C}$, near the thermal optimum for growth (Mayfield and Cech 2004; Van Eenennaam et al. 2005; Poletto et al. 2018).

The three individuals continuously tracked in 2008 were tagged with a coded depth and temperaturesensing ultrasonic transmitter (VEMCO, V9TP-2 L). Each transmitter was cylindrical ( $9 \mathrm{~mm}$ diameter and $29 \mathrm{~mm}$ length, $4.7 \mathrm{~g}$ mass in water), and had a battery life of 16 days. A slightly smaller coded transmitter was used (VEMCO, V9TP-1 L) for the remaining three tagged fish tracked in 2010. This transmitter was $9 \mathrm{~mm}$ in diameter, $24 \mathrm{~mm}$ length, $3.6 \mathrm{~g}$ in air, and was configured with a short interval between pulse bursts. Custom programming allowed a 14 day off time between surgery and release date. These coded transmitters had a battery life of 7 days. Generally a 3-7\% tag to body weight ratio is considered acceptable in tagging studies (Anglea et al. 2004; Lacroix et al. 2004; Ammann et al. 2013); however, with juvenile sturgeon mass is rarely limiting with respect to tag implantation. Rather, the tubular morphology of sturgeon, (i.e. small width to length ratio of the peritoneal cavity) generally limited the size of fish to be tagged. Tag to body weight ratios were estimated at $\leq 1.5 \%$. Rearing for all YOY individuals originating from the RBDD sampling lasted for approximately 1 year from the time of capture. All sturgeon in this study were reared to a fork length $>350 \mathrm{~mm}$ prior to tagging. Miller et al. (2014) conducted a study indicating that the incision wounds healed in fish of this size and both growth and swim speeds were not statistically different between tagged, sham, and control groups.

Fish were anesthetized prior to surgery in a knockout bath consisting of $350 \mathrm{mg} / \mathrm{L}$ of tricaine methanesulfonate (MS-222) buffered with $600 \mathrm{mg} / \mathrm{L}$ of $\mathrm{NaCl}$ and $420 \mathrm{mg} / \mathrm{l}$ of $\mathrm{NaHCO} 3$. The juveniles were placed ventral side up in a surgical cradle and gills were 


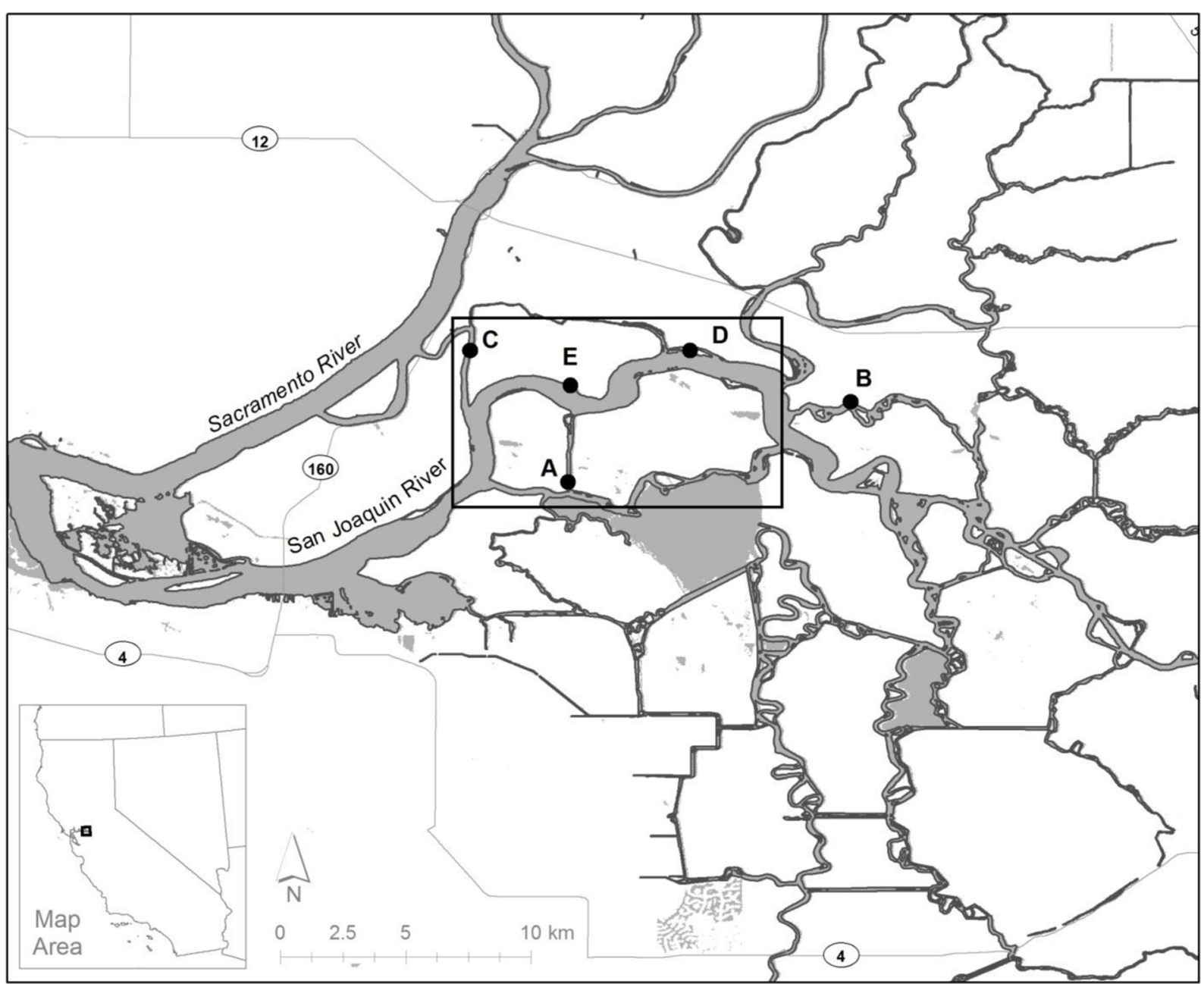

Fig. 1 Map of the central Sacramento - San Joaquin Delta. The general study area is identified by the boxed outline, Fisherman's Cut (A), Potato Slough (B), and Three-mile Slough (C). Additional locations of interest include the release location of Green
Sturgeon at San Andreas Shoal (D) and Santa Clara Shoal (E). Note that the State and Federal pumping facilities are located to the south of HWY 4 along the Old River stretch of the San Joaquin River

Juvenile sturgeon reared in 2008 were transported and released in the SSJ Delta the day after tagging was conducted. The one individual captured at the pumping facilities in 2008 was tagged and released the following day in the same location. Tagged sturgeon in 2010 were held for a period of two weeks to monitor their recovery, and then released. All Green Sturgeon were released near Santa Clara Shoal within the main-stem San Joaquin River (E, Fig. 1). Continuous mobile tracking procedures and environmental data collection using an onboard environmental water quality sonde followed the methods described in Thomas et al. (2013). Individual track times were limited by the 7-day life of transmitters. Trackers attempted to stay in close 
proximity to fish, intermittent loss of individuals did occur, but fish were generally relocated within a short time (5-15 min). Proximity to fish during mobile tracking was maintained by adjusting the directional hydrophone left and right in the direction of the fish. This type of hydrophone constrains the lateral field in which the fish can be detected and provides a course bearing with which to follow the fish. We utilized the gain controls of the VR100 to limit the distance from the boat to the fish. Positioning the vessel such that the tag signal was equally strong in all directions indicated that the fish was nearly beneath the vessel.

\section{Movement analysis}

Individual tracks were analyzed using the adehabitatLT package (Calenge 2006) and implemented using R (version 3.0.2, available at: www.R-project.org). Basic descriptive parameters of the trajectories such as step order, step length, and absolute angle of step were calculated within the r-package "adehbitatLT" (see Calenge et al. 2009 for full description). Distributions of turn angles used to analyze rheotaxis were processed with the circular statistic program (Oriana, Version 3, Wales, U.K.). In order to identify differences in behavioral states (encamped vs. directed movement), trajectories were analyzed using the First Passage Time (FPT) method that quantifies the time spent in a given area (Fauchald and Tveraa 2003; Freitas et al. 2008). Excluding the beginning and end of the track, each recorded position is associated with a circle of a given radius (r). Recorded positions with high FPT values reflect no or little movement of the animal (encamped) and positions with low FPT values reflect higher movement rates and less time spent in localized space, these were defined as directed movements. Preliminary analyses require the use of a range of lengths for the radius (r) because first-passage time values are scale dependent (i.e., a function of the radius (r) of the circle drawn encompassing each relocation). The radius resulting in the maximum natural log variance of FPT is the radius that is best able to differentiate between areas with high and low FPT values. Movement rates were calculated using the difference in step length for bursts identified as sustained movement or periods having low FPT. We examined the relationship between transmitter depth and depths measured at the boat during the track to determine the position of juvenile Green Sturgeon in the water column.
Measurements of water temperature, tidal height, and discharge, were compiled from the U.S. Geological Survey (USGS) station at Three-Mile Slough near its junction with the San Joaquin River (California Data Exchange Center [CDEC] station identification TSL; CDWR 1996). Measurements of conductivity were compiled from the U.S. Bureau of Reclamation (USBR) station at San Andreas Landing (CDEC station identification SAL; CDWR 1996).

\section{Results}

Continuous tracking of juvenile sturgeon began from 1 $\mathrm{d}$ to $14 \mathrm{~d}$ post-tagging. Total duration of tracks ranged from $16 \mathrm{~h} 15 \mathrm{~m}$ to $109 \mathrm{~h} 11 \mathrm{~m}$ (Table 1). Five of six sturgeon remained in the main-stem of the San Joaquin River for the entirety of the tracks (Fig. 2). Only one sturgeon, GS2, left the main stem. While this was a departure from the other tracks, the movements of GS2 outside of the main stem was a brief period of time relative to the remainder of this individuals track and all others. All individuals exhibited fidelity to the San Joaquin River channel. The distance between the lowest downstream position and the upstream most position of all fish was estimated at $14.6 \mathrm{~km}$ of river. Total linear distances moved by individuals ranged from $3.6 \mathrm{~km}$ for GS3 to $12.3 \mathrm{~km}$ for GS2. Calculations of total movement, estimated by time elapsed and the distance between steps, were wide ranging. GS2 moved a total of $110 \mathrm{~km}$ as measured by individual steps within the trajectory. Similarly GS 4 and GS 5 moved $106.5 \mathrm{~km}$ and $96.2 \mathrm{~km}$ respectively. In both of these cases the total linear movement for each were estimated at $11.9 \mathrm{~km}$ and $12.2 \mathrm{~km}$ respectively. Both GS1 and GS6 showed greater total movement from step lengths, $89.2 \mathrm{~km}$ and $75.1 \mathrm{~km}$, as compared to the linear distance moved, indicating that these two individuals exhibited more localized activity during the course of tracking.

Net movement during all tidal phases indicate that movements with the flow (either during ebb or flood phases) were made more frequently compared to movements against the flow. Of the 84 tidal periods over the course of the six tracks, net movements of less than $10 \mathrm{~m}$ made up $6 \%$ of the total possible movements ( 5 of 84 ). There were 39 downstream movements ( $46 \%$ of the total), and 29 upstream movements (36\% of the total). Of the 39 downstream movements, just over half (21 of 39) were made in the general current direction in the 
Table 1 Biological information and track data for six acoustically tracked juvenile Green Sturgeon in the Sacramento-San Joaquin Delta

\begin{tabular}{lllllll}
\hline Study year & Fish ID & Origin & FL/TL (cm) & Weight $(\mathrm{g})$ & Start of track & Duration (h:min) \\
\hline 2008 & GS1 & Tracy Fish Salvage Facility & $43.0 / 47.0$ & 381 & $7 / 21 / 2008$ & $16: 15$ \\
2008 & GS2 & RBDD & $45.3 / 50.2$ & 600 & $9 / 29 / 2008$ & $91: 17$ \\
2008 & GS3 & RBDD & $38.2 / 42.7$ & 310 & $12 / 15 / 2008$ & $98: 12$ \\
2010 & GS4 & RBDD & $46.3 / 52.1$ & 624 & $8 / 2 / 2010$ & $109: 05$ \\
2010 & GS5 & RBDD & $52.4 / 53.9$ & 678 & $8 / 27 / 2010$ & $109: 11$ \\
2010 & GS6 & RBDD & $50.5 / 57.8$ & 625 & $10 / 18 / 2010$ & $98: 00$ \\
\hline
\end{tabular}

presence of the ebb tide. Similarly, of the 29 upstream movements, just over half were made in the current direction of the incoming tide.

Individual sturgeon exhibited variability in their patterns of movement during the course of tracks. A selected example, Fig. 3 illustrates both negative and positive rheotaxis during two separate ebb tidal cycles for individual GS4 [(a) Rayleigh Z2.925, $p \leq 0.05$; (b) Rayleigh $\mathrm{Z7.605,} p \leq 0.01]$. Worth noting these are not simply orientation into a current or away from a current but rather represent movement with and against the flow. The median rate of movement, calculated from selected sustained bouts of directional movement ranged from $0.42-0.95 \mathrm{~ms}^{-1}$ (Table 2).

The maximized variance of FPT values was determined to be a radius, $\mathrm{S}(\mathrm{r})$, equal to $15 \mathrm{~m}$. First passage times estimated using the optimal circle radius were plotted against day and night periods for each track. When combining all six fish, tracks accounted for 23 nights (sunset to sunrise) and 17 days (sunrise to sunset).

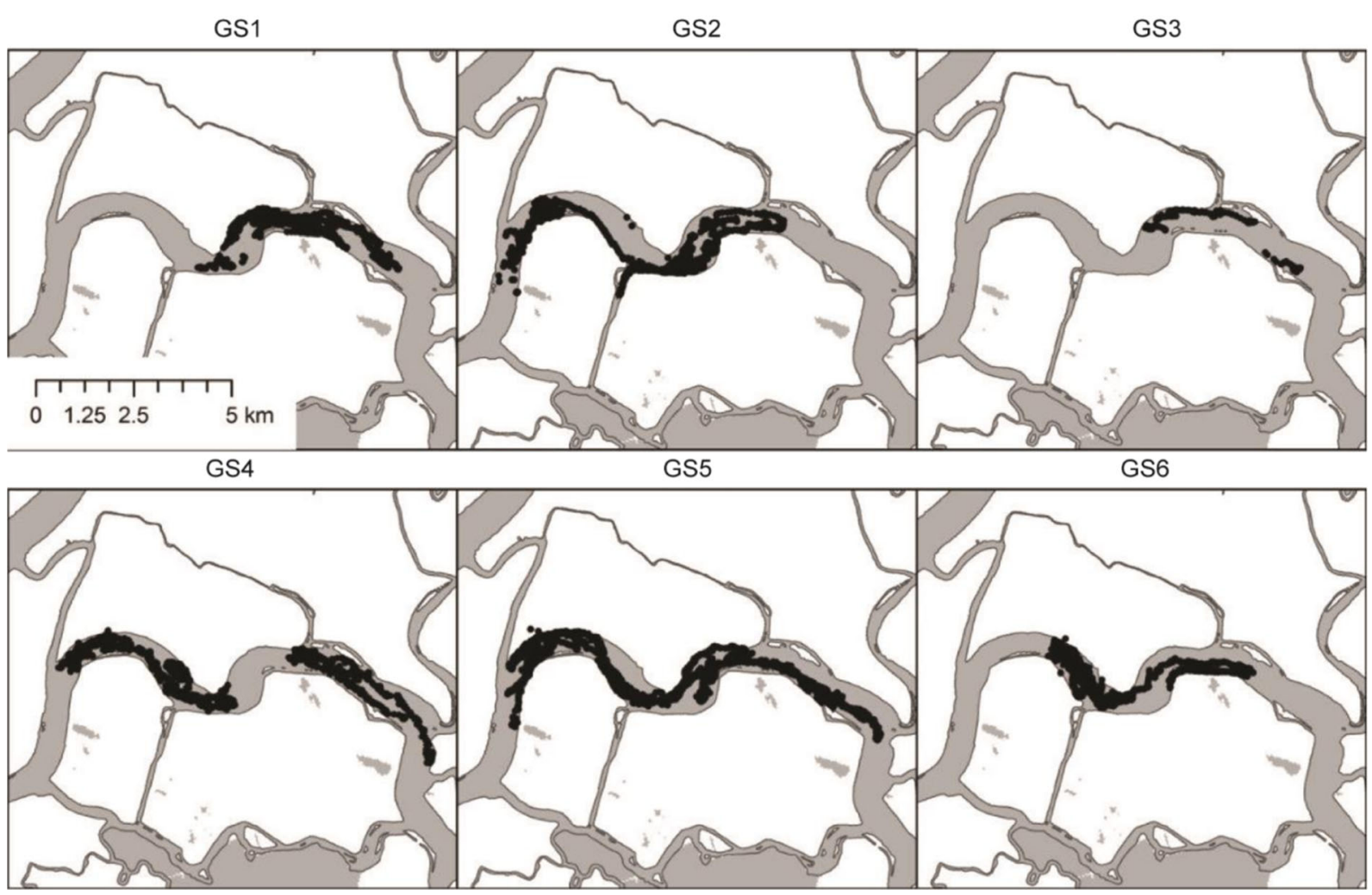

Fig. 2 General movements, shown with black, of six juvenile Green Sturgeon within the main stem San Joaquin River. All tracked individuals stayed within the study area for the duration of tracks. Panels from upper left to upper right represent tracks of GS1, GS2, and GS3. Panels from lower left to lower right represent tracks of GS4, GS5, and GS6 


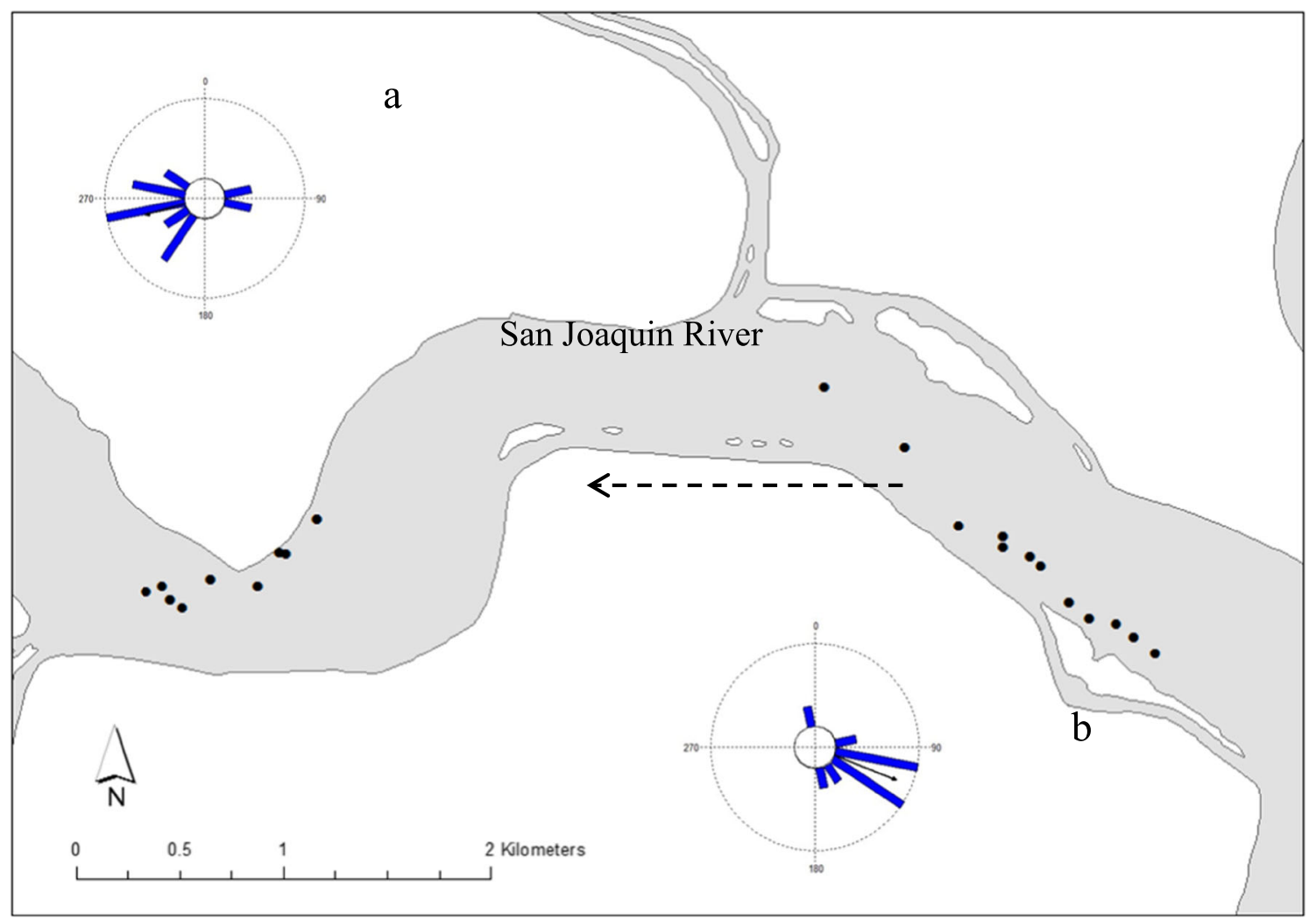

Fig. 3 Sub-set of directional movements of juvenile Green Sturgeon GS4 during ebb tides in the main stem San Joaquin River during 5 Aug 2010 (a) and 3 Aug 2010 (b). The dashed line

There was considerable individual variation in first passage times during periods of day and night (Fig. 4). For example, GS2 showed increased FPTs ranging between 1.5 to $2 \mathrm{~h}$ during three consecutive days between 30 September 2008 and 2 October 2008. Individual GS3 also showed high FPTs on the order of three hours during the day of 17 December 2008. In contrast, other sturgeon were observed to have higher FPTs during days. For example, GS4 had higher FPTs varying from

Table 2 Median rates of movement $\left(\mathrm{ms}^{-1}\right)$, presented for subset of directional movement

\begin{tabular}{lll}
\hline Fish ID & Median Rate & SE \\
\hline GS1 & 0.54 & 0.05 \\
GS2 & 0.95 & 0.12 \\
GS3 & 0.80 & 0.05 \\
GS4 & 0.60 & 0.03 \\
GS5 & 0.52 & 0.05 \\
GS6 & 0.42 & 0.10 \\
\hline
\end{tabular}

indicates the general direction of ebb flows. Note the negative rheotaxis identified in the circular distribution of step angles (a) and positive rheotaxis shown in (b)

1.5 to 3 h during nights 1,2 and 4 . Sturgeon GS5 had FPTs varying from 2.5 to $7 \mathrm{~h}$ during night 4 (Fig. 4).

Individual sturgeon GS1 and GS5 [days 1, 3, and 4] showed decreases in FPTs at sunrise. Conversely, increases in first passage times at sunset were observed for GS5 [days 1 and 4], GS2 [days 1-3], and GS3 [days 14] (Fig. 4). Sturgeon GS5 held for an extended period of time $(\sim 10 \mathrm{~h})$ in one location on night 4 of the track, resulting in high FPT values compared to the rest of the track. Individual GS6 held for several hours in several different locations during the first 1.5 days of the track, then moved consistently throughout the rest of the track. This resulted in high FPTs for the first portion of the track and lower FPTs during the latter portion of the track (Fig. 4).

Juvenile Green Sturgeon utilized a range of water depths during tracks. Plotted points of tag depth and bathymetry depth for the tracks of GS4, GS5, and GS6 positively related with tag depths falling slightly above the unity line. Fish depth measurements, where fish appear to exceed bathymetric depth, is largely a function 


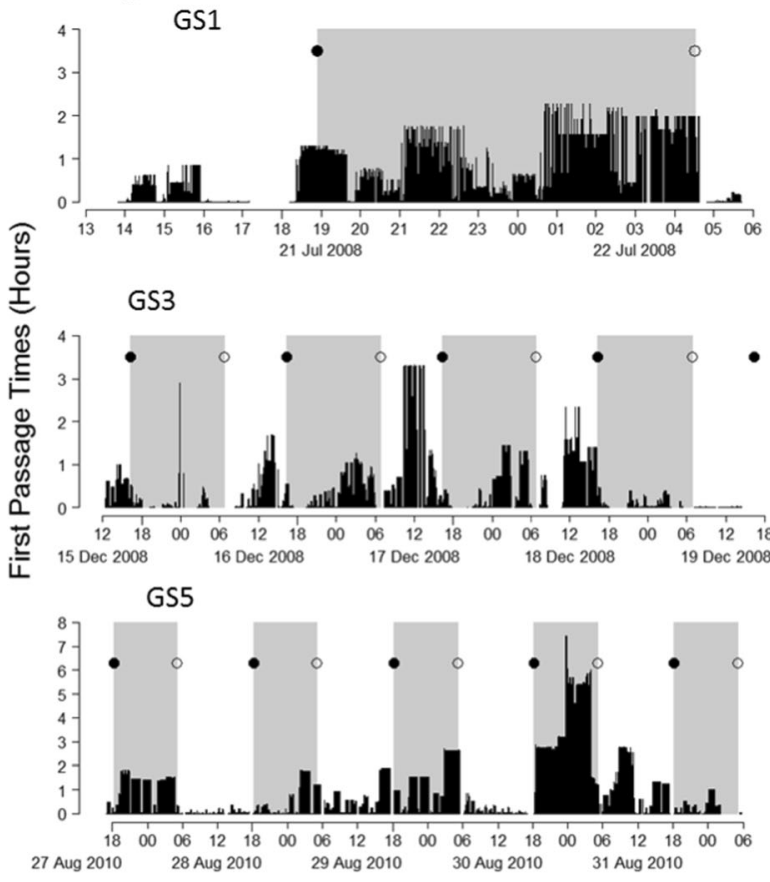

Fig. 4 First passage times (black vertical lines) of each tracked juvenile Green Sturgeon (GS1 - GS6; panels a - f) in the Sacramento-San Joaquin Delta during 2008 and 2010. Shaded

of vessel lag and the associated sensor error (though minimal). Generally, fish depth sensor measurements indicated that fish positioned themselves at or near the bottom of the water column as illustrated by a sub-set of depths from a directional movement bout of GS2 (Fig. 5). Fish depth readings from continuous transmitters ranged from $0.2 \mathrm{~m}$ to $25.0 \mathrm{~m}$ during all six tracks, with the shallowest readings associated with the release of the fish. After the initial release period, depth readings from most sturgeon were greater than five meters, with the exception of GS3. Median depths utilized for each fish ranged from $4.1 \mathrm{~m}$ (GS3) to $12.1 \mathrm{~m}$ (GS5). The distributions of depths were fairly uniform, with the exceptions of GS3 and GS6, which showed leftskewed distributions toward shallower depths (Fig. 6). Additional environmental variables encountered by sturgeon varied by time and by fish and are summarized in Table 3.

\section{Discussion}

Juvenile Green Sturgeon exhibited a broad range of movement behaviors throughout the study. While
GS2

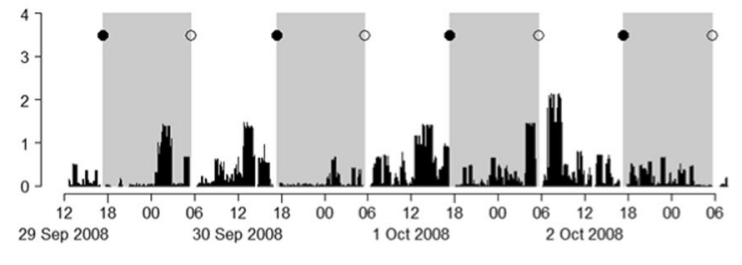

GS4

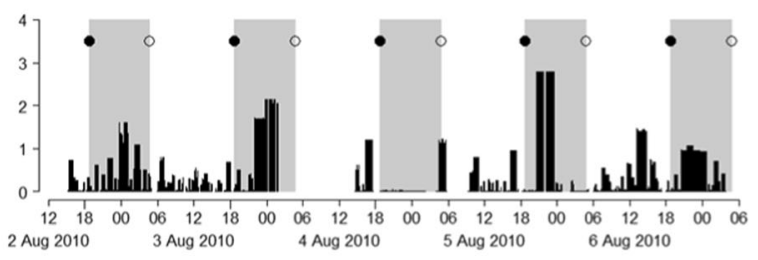

GS5

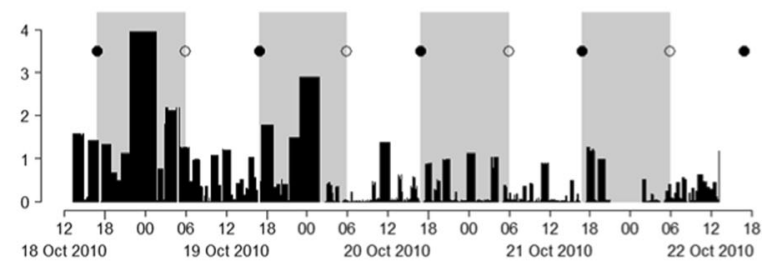

rectangles represent periods of night based on calculated times of sunrises (open circles) and sunsets (closed circles) for each track. Note difference in Y-axis scaling for GS5

directional movements were generally characterized as into the flow more frequently than against the flow, it is apparent that sturgeon do move independently of tidal direction. Directed movements which were positive rheotaxis may be emblematic of foraging behavior. Unique adaptations such as barbules, electro-receptors, olfactory sense, and morphology allow for foraging in conditions where vision is limited if not non-existent. Of particular importance to sturgeon feeding behavior is their olfactory sense (Webb 1986; Kasumyan 1994; Kasumyan 1999; Kogut 2008), and by orienting into the current the scent of prey items is carried to sturgeon. Alternatively, directed movement bouts where negative rheotaxis was exhibited may suggest a switch in behavioral state from feeding to roaming through flow assisted transport. Previous studies of adult and sub-adult movements have shown sturgeon exhibiting both directed movements and encamped movements within San Francisco Bay (Kelly et al. 2007). Results from this study describe larger sturgeon making directed movements in the upper $20 \%$ of the water column. Our results did not show that juvenile sturgeon moved up in the water column to make directed movements. It is possible that differences in flow velocities and potentially the 


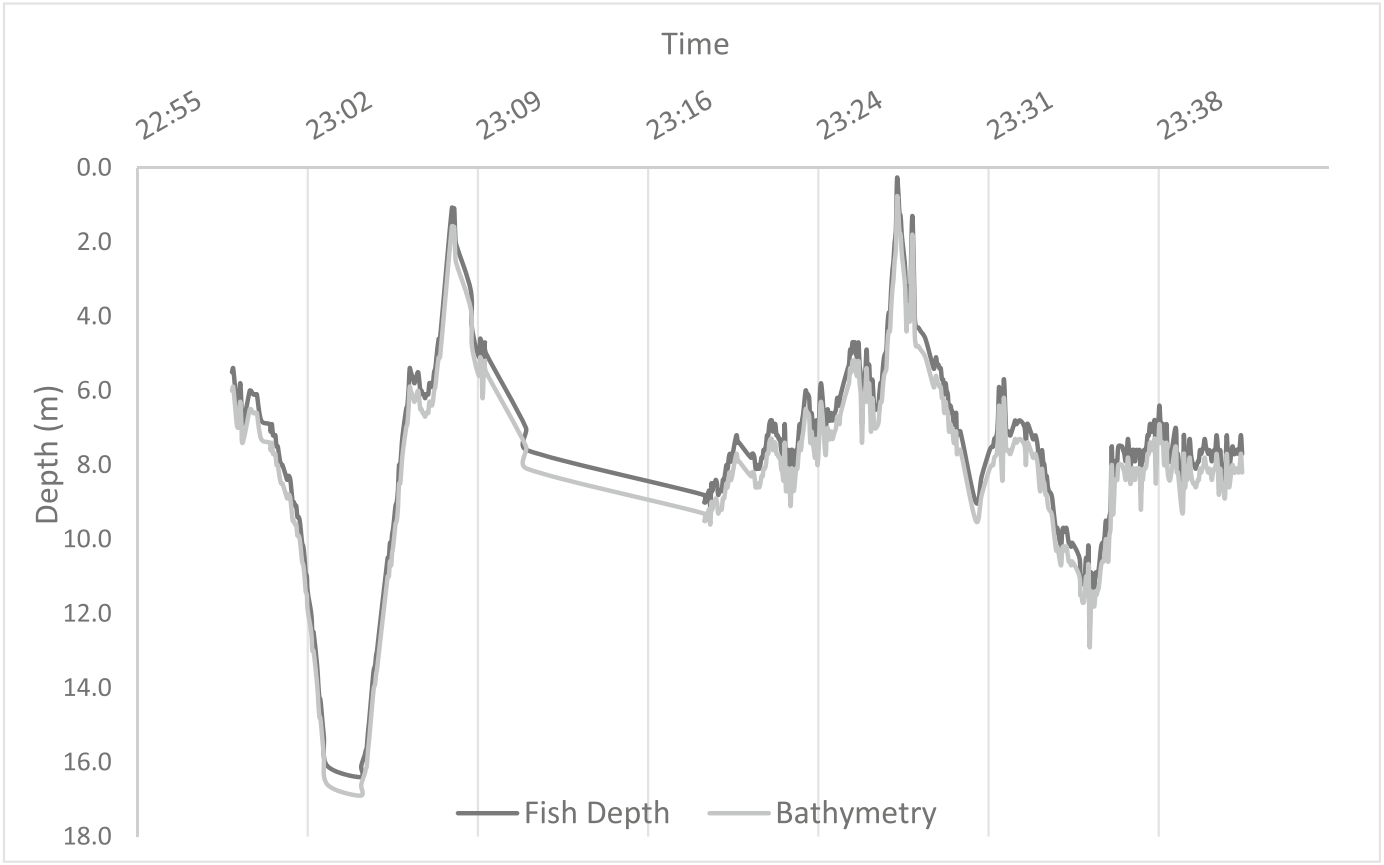

Fig. 5 Subset of GS2 track showing bathymetry in grey and fish depth reported by the depth sensor black

size of the fish between the two may affect the behaviors relating to where in the vertical water column sturgeon are found. It could be hypothesized that the ability to move up into faster flow velocities nearer the surface is a function of fish size and swimming performance as a function of those velocities. Therefore, it might be
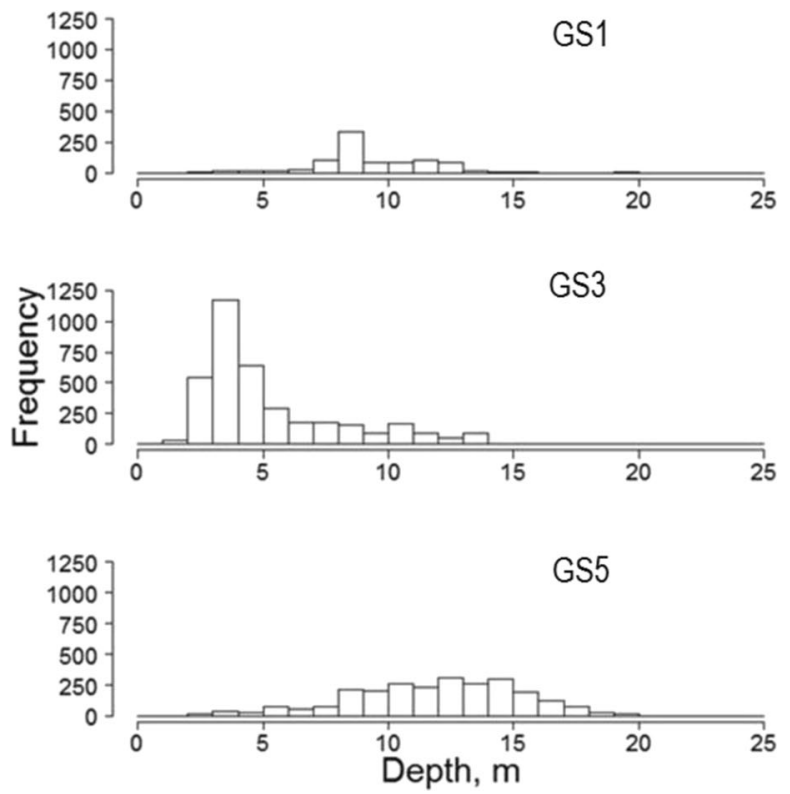

Fig. 6 Frequencies of fish depth readings from continuous transmitters for each juvenile Green Sturgeon (GS1- GS6) tracked in the mainstem San Joaquin River in 2008 and 2010
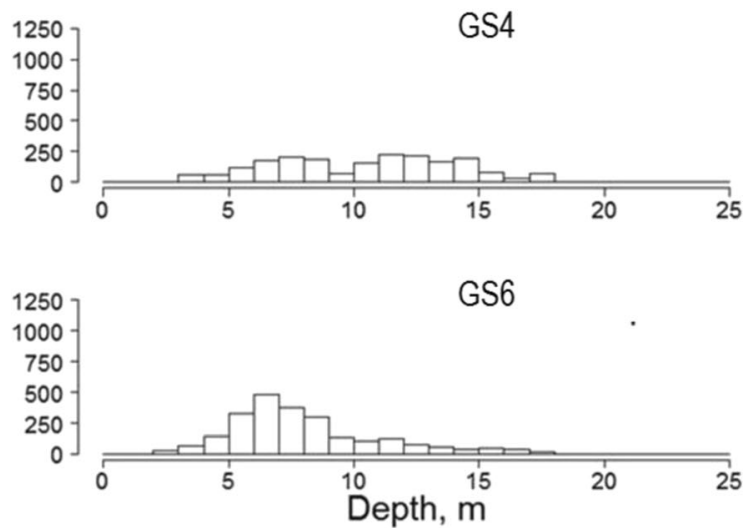

expected that smaller fish with reduced swim capacity in higher velocities show a greater preference nearer the substrate where flow velocity is typically reduced relative to the remainder of the water column.

We identify significant variability both within and between individuals with respect to FPTs during days

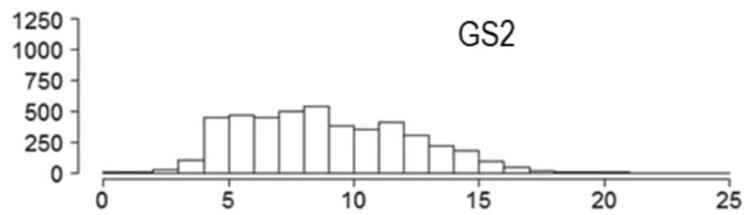


Table 3 Summary of temperature, discharge, turbidity, and conductivity from Three Mile Slough (CDEC Station Identification TSL) for each fish. Reported as mean \pm standard deviation (SD)

\begin{tabular}{llllll}
\hline Fish ID & Tracking Period & Temperature $\left({ }^{\circ} \mathrm{C}\right)$ & Discharge $\left(\mathrm{m}^{3} \mathrm{~s}^{-1}\right)$ & Turbidity $(\mathrm{NTU})$ & $\mathrm{Conductivity}\left(\mu \mathrm{cm}^{-1}\right)$ \\
\hline GS1 & 21-22 July 2008 & $21.3 \pm 0.3$ & $-303 \pm 487$ & $18.1 \pm 1.5$ & $587 \pm 85$ \\
GS2 & 29 Sept - 3 Oct 2008 & $20.6 \pm 0.2$ & $-48 \pm 596$ & $12.5 \pm 3.5$ & $780 \pm 123$ \\
GS3 & 15-19 Dec 2008 & $9.3 \pm 0.5$ & $-25 \pm 638$ & $10.2 \pm 3.4$ & $1578 \pm 626$ \\
GS4 & 2-7 Aug 2010 & $21.1 \pm 0.3$ & $-100 \pm 513$ & $11.8 \pm 1.7$ & $325 \pm 106$ \\
GS5 & 27 Aug - 1 Sept 2010 & $21.2 \pm 0.3$ & $-51 \pm 498$ & $9.8 \pm 1.8$ & $663 \pm 245$ \\
GS6 & 18-22 Oct 2010 & $18.7 \pm 0.3$ & $-53 \pm 529$ & $7.5 \pm 1.6$ & $813 \pm 252$ \\
\hline
\end{tabular}

vs. nights. We saw no clear preference for either increased or decreased activity as reported by FPTs, during days or nights. It could be concluded that despite convention, sturgeon activity may not necessarily be driven by day or night. An alternative hypothesis is that increased movement is a response to flow velocities and tidal cycle. While this study lacks the capability to identify behavioral responses to perceived flow fields, future studies should consider these interactions and how they affect SSJ Delta transport and residency.

Historically the SSJ Delta was a complex and dynamic ecosystem comprised of shallow and deep tidal channels, wetlands, seasonal ponds, and a range of riparian vegetation (Whipple et al. 2012). These are all influenced by the seasonal shifts of tidal and fluvial processes. With California's gold rush came the beginning of the physical changes that the SSJ Delta ecosystem would incur over the next hundred and fifty years. The SSJ Delta was drastically changed through this period of land reclamation, which leveed most, if not all, of the wetland habitat creating a new network of homogenous waterways. It is estimated today that there is approximately 470,000 acres (190,200 ha) of leveed lands in agricultural production within the SSJ Delta (Whipple et al. 2012). Along with these physical changes came agricultural demands, and a growing population. Water transport became one of the primary functions of the SSJ Delta and the subsequent freshwater/tidal processes, volume, and timing of runoff from major tributaries were substantially altered from pre-settlement (Whipple et al. 2012). It should not be lost that the rate of landscape and hydrodynamic process change within the system occurred within only two generations of the species life span, a rather short timeline given the evolutionary history of such a primitive species.

Juvenile Green Sturgeon were generally oriented near the bottom as illustrated in Fig. 6. Drag coefficients, substrate, and subtle bathymetric variability are certainly all considerations for why flow velocities may be less near the bottom which would potentially argue for those cases where sturgeon move in varied directions independent of tide. We observed benthic orientation across a range of depths, including those within the dredged portion of the navigational channel which is the majority of the San Joaquin River in this reach. While frequency of occupation within those depths characterized as navigational channel $(10-20 \mathrm{~m})$ were less than those characterized as shoal $(0-10 \mathrm{~m})$, all individuals utilized the navigational channel in some capacity. Green Sturgeon morphology, physiology, sensory systems, and preferred diets are all adaptive attributes which allow for successful near the benthos (Webb 1986; Kasumyan 1994; Kasumyan 1999; Kogut 2008). Preference for benthic orientation does beg the question as to whether human activities such as dredging indirectly or directly affect juvenile Green Sturgeon. Given preference for being near the bottom, one would assume some risk or exposure to navigational channel dredging activities. Results from laboratory swimming performance studies for Lake and Pallid Sturgeon suggest that for sturgeon in the 10-90 cm length classes show higher levels of risk when modeled with dredge flow fields. However, elevated risks were shown to be limited to within the $1.25 \mathrm{~m}$ radius of the drag head dredge (Hoover et al. 2011). Although it is worth noting, perceived risk to Green Sturgeon within the 
current population structure may be assuaged by the low probability of dredge encounter, particularly given the rarity of the species within the system.

In contrast to the intensive research and monitoring of salmonids in the SSJ Delta, little research has been directed towards the juvenile life history stage of Green Sturgeon. Information on habitat usage, spatial distribution, and movement patterns of juvenile GS within the SSJ Delta are particularly lacking and are limited to Radtke (1966). Radtke (1966) reported 1) the presence of juvenile Green Sturgeon at a single location, Santa Clara Shoal, (Fig. 1E), 2) identified two distinct size classes ranging from 20 to 31 and $32-58 \mathrm{~cm}$, and 3 ) described their diet. The size ranges documented by Radtke (1966), are similar to salvage collections from the State and Federal Water Project pumping facilities in the southern SSJ Delta. Juvenile Green Sturgeon salvaged from the south SSJ Delta pumping facilities ranged in size from 28 to $38 \mathrm{~cm}$ (Adams et al. 2002). Age at length from the Klamath River using otoliths indicate that individuals collected in the SSJ Delta would range from one to four years of age (Nakamoto et al. 1995). Assuming that the age at length information taken from Klamath River Green Sturgeon corresponds with sDPS Green Sturgeon, it could be hypothesized that a substantial part of the juvenile life stage is spent in the nursery grounds of the SSJ Delta.

Given the potential for high residency rates in SSJ Delta habitats, it is imperative to consider direct and indirect stressors to the species in this ever-changing ecosystem. Due to the many changes in the SSJ Delta ecosystem, evidence suggesting a declining population, climate change, and increasing demand for water, fisheries managers are in a position of balancing the needs of people with that of Green Sturgeon. However, this implies we understand what the biological needs of Green Sturgeon are, and more specifically the needs of juveniles rearing in the SSJ Delta. With respect to the juvenile life stage of Green Sturgeon, such a task can only be qualified by first developing a fundamental understanding of the basic biology of the life stage. While our study is unable to expand results to the broader population, we provide a first-look at the behaviors and use of currently available habitat. Future work should include studies which focus on a much broader understanding of the temporal residency, spatial use of available habitats, and the trophic ecology, all of which support necessary growth prior to ocean entry. However, it is worth noting that occurrence of juvenile
Green Sturgeon in existing monitoring programs is exceedingly rare. To compound the issues of uncertainty about the fundamental biology of the species, it is worth noting that at this time there is no specific monitoring program which specifically targets this life stage within the lower system. Future recovery actions should most certainly incorporate species specific monitoring by life stage and in particular, the development of new strategies and methods with which to access these fish for the purpose of gaining new insights.

Acknowledgments We would like to thank members of U.C. Davis Department of Wildlife, Fish, and Conservation Biology who assisted with the long hours of tracking, Anna Steel, Gabriel Singer, and Alex Hearn. We would like to thank our partners at the U.S. Fish and Wildlife Service, Red Bluff office for their role in ensuring we had juvenile Green Sturgeon to study. The project was funded through California Department of Fish and Wildlife (Agreement \#E0783004) and U.S. Bureau of Reclamation (Agreement \#R10AC20012). Additional support was provided by California Agricultural Experimental Station of the University of California Davis to N.A.F. (CA-D-ASC-2091-H). This work was approved through the University of California, Davis IACUC (\#13053).

Open Access This article is distributed under the terms of the Creative Commons Attribution 4.0 International License (http:// creativecommons.org/licenses/by/4.0/), which permits unrestricted use, distribution, and reproduction in any medium, provided you give appropriate credit to the original author(s) and the source, provide a link to the Creative Commons license, and indicate if changes were made.

\section{References}

Adams PB, Grimes CG, Hightower JELST, Moser MM (2005) Green sturgeon (Acipenser medirostris) status review update

Adams PB, Grimes CG, Hightower JE, Lindley ST, Moser MM (2002) Status review for North American green sturgeon, Acipenser medirostris. Final Report to Southwest Region, NOAA Fisheries, Long Beach, CA.

Adams PB, Grime C, Hightower JE, Lindley ST, Moser MM, Parsley MJ (2007) Population status of North American green sturgeon, Acipenser medirostris. Environ Biol Fish 79:339-356

Allen PJ, Cech JJ (2007) Age/size effects on juvenile green sturgeon, Acipenser medirostris, oxygen consumption, growth, and osmoregulation in saline environments. Environ Biol Fish 79:211-219

Ammann A, Michel C, MacFarlane RB (2013) The effects of surgically implanted acoustic transmitters on laboratory growth, survival and tag retention in hatchery yearling Chinook salmon. Environ Biol Fish 96(2-3):135-143. https://doi.org/10.1007/s10641-011-9941-9 
Anglea SM, Geist DR, Brown RS, Deters KA (2004) Effects of acoustic transmitters on swimming performance and predator avoidance of juvenile Chinook Salmon. N Am J Fish Manag 24:162-170

Beamesderfer RCP, Simpson ML, Kopp GJ (2007) Use of life history information in a population model for Sacramento green sturgeon. Environ Biol Fish 79:315-337

Brown K (2007) Evidence of spawning by green sturgeon, Acipenser medirostris, in the upper Sacramento River, California. Environ Biol Fish 79(3-4):297-303. https://doi. org/10.1007/s10641-006-9085-5

Calenge $\mathrm{C}$ (2006) The package adehabitat for the R software: a tool for the analysis of space and habitat use by animals. Ecol Model 197:516-519

Calenge C, Dray S, Royer-Carenzi M (2009) The concept of animals' trajectories from a data analysis perspective. Ecological Informatics 4 (1):34-41. https://doi.org/10.1016 /j.ecoinf.2008.10.002

California Department of Water Resources (2013) Bay Delta Conservation Plan: Public Draft. Published by ICF International (ICF 00343.12). Sacramento, California, p 2, Section 2.2

California Department of Water Resources (1996) California Data Exchange Center. https://cdec.water.ca.gov/

DuBoise J, Matt T, Harris M (2010) Field season summary for the adult sturgeon population study. California Department of Fish and Wildlife, pp 1-10

Erickson DL, Hightower JE (2007) Oceanic distribution and behavior of green sturgeon. Am Fish Soc Symp 56:197-211

Erickson DL, Webb MAH (2007) Spawning periodicity, spawning migration, and size at maturity of green sturgeon, Acipenser medirostris, in the Rogue River, Oregon. Environ Biol Fish 79(3-4):255-268. https://doi. org/10.1007/s10641-006-9072-x

Erickson DL, North JA, Hightower JE, Weber J, Lauck L (2002) Movement and habitat use of green sturgeon Acipenser medirostris in the Rogue River, Oregon, USA. J Appl Ichthyol 18(4-6):565-569

Fauchald P, Tveraa T (2003) Using first-passage time in the analysis of area restricted search and habitat selection. Ecology 84(2):282-288

Freitas C, Kovacs KM, Lydersen C, Ims RA (2008) A novel method for quantifying habitat selection and predicting habitat use. J Appl Ecol 45:1213-1220

Hamda NT, Martin B, Poletto JB, Cocherell DE, Fangue NA, Van Eenennaam J, Mora EA, Danner E (2019) Applying a simplified energy-budget model to explore the effects of temperature and food availability on the life history of green sturgeon (Acipenser medirostris). Ecol Model 395:1-10. https://doi.org/10.1016/j.ecolmodel.2019.01.005

Heublein JC, Kelley JT, Crocker CE, Klimley AP, Lindley ST (2009) Migration of green sturgeon, Acipenser medirostris, in the Sacramento River. Environ Biol Fish 84:245-258

Hoover JJ, Boysen KA, Beard JA, Smith H (2011) Assessing the risk of entrainment by cutterhead dredges to juvenile lake sturgeon (Acipenser fulvescens) and juvenile pallid sturgeon (Scaphirhynchus albus). J Appl Ichthyol 27(2):369-375. https://doi.org/10.1111/j.1439-0426.2011.01746.x

Kasumyan AO (1994) Olfactory responsivity of sturgeon fishes to free amino-acids. Biofizika 39(3):522-525
Kasumyan AO (1999) Olfaction and taste senses in sturgeon behaviour. J Appl Ichthyol 15(4-5):228-232. https://doi. org/10.1111/j.1439-0426.1999.tb00240.x

Kelly JT, Klimley AP, Crocker CE (2007) Movements of green sturgeon, Acipenser medirostris, in the San Francisco Bay estuary, California. Environ Biol Fish 79:281-295

Kogut N (2008) Overbite clam, Corbula amurensis, defecated alive by white sturgeon, Acipenser transmontanus. Calif Fish Game 94(3):143-149

Lacroix GL, Knox D, McCurdy P (2004) Effects of implanted dummy acoustic transmitters on juvenile Atlantic Salmon. T Am Fish Soc 133:211-220

Lindley ST, Moser MM, Erickson DL, Belchik M, Welch DW, Rechiski E, Klimley AP, Kelly JT, Heublein JC (2008) Marine migration of North American green sturgeon. Trans Am Fish Soc 137:182-194

Mayfield RB, Cech JJ (2004) Temperature effects on green sturgeon bioenergetics. Trans Am Fish Soc 133(4):961-970. https://doi.org/10.1007/s10641-013-0167-x

Miller, E.A., Froehlich, H.E., Cocherell, D.E. et al. Environ Biol Fish (2014) 97: 647.

Moser MM, Lindley ST (2007) Use of Washington estuaries by subadult and adult green sturgeon. Environ Biol Fish 79: 243-253

Moser ML, Israel JA, Neuman M, Lindley ST, Erickson DL, McCovey BW, Klimley AP (2016) Biology and life history of green sturgeon (Acipenser medirostris Ayres, 1854): state of the science. J Appl Ichthyol 32:67-86. https://doi. org/10.1111/jai.13238

Moyle P (2002) Inland fishes of California, 2nd edn. Univeristy of California Press, Berkeley

Nakamoto RJ, Kisanuki TT, Goldsmith GH (1995) Age and growth of Klamath River green sturgeon (Acipenser medirostris). U. S. Fish and Wildlife Service Report. Project 93-FP-13, U.S. Fish and Wildlife Service, Arcata, CA.

National Marine Fisheries Service (2006) Endangered and Threatened Wildlife and Plants: Threatened Status for Southern Distinct Population Segment of North American Green Sturgeon Federal Register. vol 71, p 17757-17766

Poletto JB, Cocherell DE, Klimley AP, Cech JJ, Fangue NA (2013) Behavioural salinity preferences of juvenile green sturgeon Acipenser medirostris acclimated to fresh water and full-strength salt water. J Fish Biol 82(2):671-685. https://doi.org/10.1111/jfb.12023

Poletto JB, Martin B, Danner E, Baird SE, Cocherell DE, Hamda N, Cech J, Joseph J, Fangue NA (2018) Assessment of multiple stressors on the growth of larval green sturgeon Acipenser medirostris: implications for recruitment of early life-history stages. J Fish Biol 93(5):952-960. https://doi. org $/ 10.1111 / \mathrm{jfb} .13805$

Poytress WR, Gruber JJ, Trachtenbarg DA, Van Eenennaam J (2009) 2008 Upper Sacramento River Green Sturgeon Spawning Habitat and Larval Migration Surveys. Annual Report of U.S. Fish and Wildlife Service to US Bureau of Reclamation, Red Bluff, CA

Poytress WR, Gruber JJ, Van Eenennaam J (2010) 2009 upper Sacramento River green sturgeon spawning habitat and larval migration survey. Annual Report of U.S. Fish and Wildlife Service to U.S. Buruau of Reclamation, Red Bluff, CA.

Poytress WR, Gruber JJ, Van Eenennaam JP, Gard M (2015) Spatial and temporal distribution of spawning events and 
habitat characteristics of Sacramento River green sturgeon. Trans Am Fish Soc 144(6):1129-1142. https://doi. org/10.1080/00028487.2015.1069213

Radtke LD (1966) Distribution of smelt, juvenile sturgeon, and starry flounder in the Sacramento-san Joaquin Delta with observations on food of sturgeon. Fish Bulletin 136:115-129

Thomas MJ, Peterson ML, Friedenberg N, Van Eenennaam JP, Johnson JR, Hoover JJ, Klimley AP (2013) Stranding of spawning run green sturgeon in the Sacramento River: postrescue movements and potential population-level effects. $\mathrm{N}$ Am J Fish Manag 33(2):287-297. https://doi.org/10.1080 /02755947.2012.758201

Thomas MJ, Peterson ML, Chapman ED, Hearn AR, Singer GP, Battleson RD, Klimley AP (2014) Behavior, movements, and habitat use of adult green sturgeon, Acipenser medirostris, in the upper Sacramento River. Environ Biol Fish 97(2):133146. https://doi.org/10.1007/s10641-013-0132-8

Van Eenennaam JP, Linares-Casenave J, Deng X, Doroshov SI (2005) Effect of incubation temperature on green sturgeon embryos, Acipenser medirostris. Environ Biol Fish 72(2): 145-154. https://doi.org/10.1007/s10641-004-8758-1

Webb PW (1986) Kinematics of lake sturgeon, Acipenser fulvescens, at cruising speeds. Can J Zool 64(10):21372141. https://doi.org/10.1139/z86-328

Whipple AA, Grossinger RM, Rankin D, Stanford B, Askevold RA (2012) Sacramento-San Joaquin Delta Historical Ecology Investigation: Exploring Pattern and Process. Prepared for the California Department of Fish and Game and Ecosystem Restoration Program. A Report of SFEIASC's Historical EcologyProgram, Publication \#672, San Francisco Estuary Institute-Aquatic Science Center, Richmond, CA

Publisher's note Springer Nature remains neutral with regard to jurisdictional claims in published maps and institutional affiliations. 